\title{
Parietal Cell Responsiveness in Duodenal Ulcer
}

\author{
K. G. WORMSLEY,* M.D., B.SC., M.R.C.P. ; M. P. MAHONEY,† M.B., M.R.C.P.
}

One of the hypotheses advanced to explain the excessive acid secretion of patients with duodenal ulcer is that the acidsecreting cells are abnormally sensitive to stimulation. We have studied the gastric response of normal individuals and of patients with duodenal ulcer to increasing amounts of a gastrinlike pentapeptide given by continuous intravenous infusion and have found no difference between the responsiveness of the stomachs of these two groups of subjects.

\section{Present Investigation}

Methods.-The subjects of this study comprised 13 normal medical students and 23 patients with duodenal ulcer. The

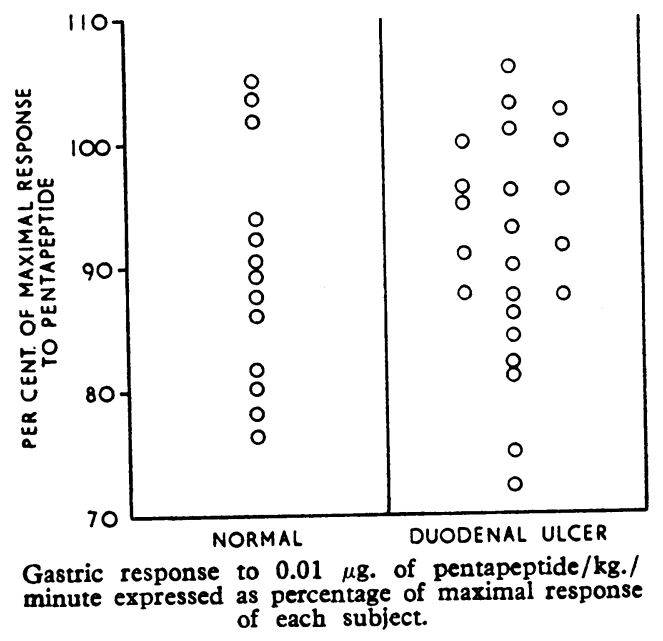

pentapeptide (I.C.I. 50,123) was given by intravenous infusion at constant rate in a dose range of 0.001 to $0.3 \mu \mathrm{g} . / \mathrm{kg}$. body weight per minute. The response to 0.001 and $0.01 \mu \mathrm{g} . / \mathrm{kg}$. was expressed as a percentage of the maximal response to pentapeptide of each subject, the maximal response being defined as

- Research Fellow, Royal Infirmary, Manchester. t Medical Tutor, Royal Infirmary, Manchester. that level of acid output which could not be increased by increasing the dose rate of pentapeptide. The statistical significance of the difference in distribution of the percentage values in the two groups was determined by means of the MannWhitney U test.

Results.-The responses to $0.001 \mu \mathrm{g}$. of pentapeptide $/ \mathrm{kg}$./ minute ranged from 49 to $83 \%$ of maximal in the normal subjects and from 47 to $74 \%$ of maximal in patients with duodenal ulcer, while the responses to $0.01 \mu \mathrm{g} . / \mathrm{kg} . /$ minute ranged from 70 to $107 \%$ of maximal in both groups of subjects (see Chart). The distribution of the ratios of submaximal to maximal gastric responses of normal individuals did not differ significantly from patients with duodenal ulcer $(P>0.09)$.

\section{Discussion and Conclusions}

Indirect evidence, induced from the ratios of basal to stimulated acid output, together with evidence from dose-response curves to histamine, prompted Hunt and Kay (1954) to conclude that gastric hyperexcitability was not the cause of hypersecretion in duodenal ulcer. This conclusion was reaffirmed in a later, more detailed analysis of the same data (Hunt, Kay, Card, and Sircus, 1963).

Our results show that the acid-secreting cells of patients with duodenal ulcer are not more sensitive to lower dose rates of pentapeptide infusion and are not stimulated maximally more easily than the parietal cells of normal subjects.

We wish to thank Dr. H. T. Howat, who placed the resources of his unit at our disposal during this study, and $\mathrm{Mr}$. H. B. Torrance for permission to study patients under their care ; Dr. J. D. Fitzgerald (Medical Division, Imperial Chemical Industries) for supplies of pentapeptide ; and Dr. R. Ollerenshaw and the staff of the department of medical illustration, Manchester Royal Infirmary, for the Chart. One of us (K. G.W.) is receiving a full-time research grant from the Medical Research Council.

\section{REFERENCES}

Hunt, J. N., and Kay, A. W. (1954). Brit. med. F., 2, 1444. W. (1963). In Pathophysiology of Peptic Ulcer, edited by S. C. Skoryna. Philadelphia. 